\title{
Towards developing a diagnostic algorithm for Chlamydia trachomatis and Neisseria gonorrhoeae cervicitis in pregnancy
}

Michael R Braddick, Jack O Ndinya-Achola, Nazir B Mirza, Francis A Plummer, Gerald Irungu, Samuel K A Sinei, Peter Piot

\begin{abstract}
$C$ trachomatis and $\boldsymbol{N}$ gonorrhoeae are major causes of maternal and neonatal morbidity and mortality in developing countries. To identify characteristics predictive of cervical infection, we examined pregnant women attending an antenatal clinic in Nairobi, Kenya. $C$ trachomatis was isolated from $14 / 178(8 \%)$, and $N$ gonorrhoeae from $17(10 \%)$; cervical infection with either pathogen was present in $28(16 \%)$. Two characteristics were independently predictive of cervical infection by logistic regression analysis; the presence of either endocervical mucopus or induced endocervical bleeding, relative risk $4 \cdot 2$ (95\% confidence interval (CI) $2 \cdot 2$ to 8.0 ) and having more than one sexual partner during pregnancy, relative risk $3.3(95 \%$ CI 1.4 to $7 \cdot 6)$. A screening programme for cervical infection which tested women with one or both risk markers would have a sensitivity of $68 \%(95 \%$ CI 51 to 85\%) and a positive predictive value of $0.35(95 \%$ CI 0.22 to 0.47$)$. In countries where resources are limited, diagnostic algorithms incorporating clinical signs and behavioural characteristics may be useful in identifying pregnant women at high risk of cervical infection.
\end{abstract}

Department of Medical Microbiology, University of Nairobi, Nairobi, Kenya

Michael R Braddick, Jack O Ndinya-Achola, Nazir B Mirza, Francis A Plummer, Gerald Irungu

Academic Department of Genito-Urinary Medicine, University College and Middlesex School of Medicine, London, UK

Michael R Braddick

Department of Medicine, University of Manitoba, Winnipeg, Manitoba, Canada

Francis A Plummer

Department of Obstetrics and Gynaecology, University of Nairobi, Nairobi, Kenya

Samuel KA Sinei

Department of Microbiology, Institute of Tropical Medicine, Antwerp, Belgium

Professor Peter Piot
Introduction

Sexually transmitted diseases (STDs) are a global problem, yet many countries lack the resources for comprehensive control programmes and are limited to treating symptomatic patients. In pregnancy $C$ trachomatis and $N$ gonorrhoeae may cause a wide range of serious complications, which include postabortal sepsis, premature delivery, and post-partum endometritis, ophthalmia neonatorum and neonatal pneumonia. $^{1-7}$

Currently diagnosis depends on sophisticated laboratory techniques, and the establishment of a network of specialised clinics is an unrealistic goal in many parts of the world. Simple, inexpensive, and rapid diagnostic techniques are needed at the primary health care level to identify high risk patients for treatment or further investigation. ${ }^{4-9}$ We have examined pregnant women and tried to identify demographic, behavioural and clinical characteristics predictive of cervical infection with $C$ trachomatis and $N$ gonorrhoeae.

\section{Methods}

All women attending an ante-natal clinic in a lower socio-economic district of Nairobi were informed about the study. and invited to participate. Women giving verbal informed consent were enrolled into the study. A demographic and pregnancy history was taken and a genital examination was performed by one examiner using pre-defined criteria. Vaginal discharge was assessed for colour: clear/white/ yellow-green, consistency: normal/frothy/curdy, odour normal/malodorous, and quantity: scanty/ normal $/$ profuse $($ scanty $=$ dry vagina, profuse $=$ discharge visible at introitus prior to speculum exam).

The cervix was cleaned with cotton wool and then examined for the presence of ectopy and ulcers. Cervical swabs were taken for $N$ gonorrhoeae and $C$ trachomatis. The first swab was assessed for colour of endocervical secretions: clear/opaque/yellowgreen (yellow-green endocervical secretions were defined as mucopus), and for induced endocervical bleeding.

Specimens for $N$ gonorrhoeae were immediately inoculated on modified Thayer-Martin media and 
Table 1 Relationship of demographic and behavioural characteristics, symptoms, and signs to cervical infection

\begin{tabular}{|c|c|c|c|c|c|}
\hline \multirow{2}{*}{$\begin{array}{l}\text { Variable } \\
\text { Mean Age (SD) in years } \\
\text { Unmaried } \\
>1 \text { Sexual Partner during Pregnancy } \\
\text { Previous STD } \\
\text { Vaginal Discharge }\end{array}$} & \multicolumn{4}{|c|}{ Cervical Infection } & \multirow[b]{2}{*}{$p$} \\
\hline & \multicolumn{2}{|c|}{ present $(n=28)$} & \multicolumn{2}{|c|}{ absent $(n=150)$} & \\
\hline $\begin{array}{l}\text { Mean Age (SD) in years } \\
\text { Unmarried } \\
\text { > 1 Sexual Partner during Pregnancy } \\
\text { Previous STD } \\
\text { Vaginal Discharge } \\
\text { Dysuria } \\
\text { Abdominal Pain } \\
\text { Frothy Vaginal Discharge } \\
\text { Profuse Vaginal Discharge } \\
\text { Yellow/Green Vaginal Discharge } \\
\text { Induced Endocervical Bleeding } \\
\text { Endocervical Mucopus } \\
\text { Clinical Cervicitis } \dagger\end{array}$ & $\begin{array}{r}23 \cdot 6 \\
14 / 27 \\
5 / 28 \\
3 / 28 \\
8 / 28 \\
3 / 28 \\
11 / 28 \\
10 / 28 \\
10 / 28 \\
6 / 28 \\
12 / 28 \\
5 / 20 \\
17 / 28\end{array}$ & $\begin{array}{l}(5 \cdot 3) \\
(52 \%) \\
(18 \%) \\
(11 \%) \\
(29 \%) \\
(11 \%) \\
(39 \%) \\
(36 \%) \\
(36 \%) \\
(21 \%) \\
(43 \%) \\
(25 \%) \\
(61 \%)\end{array}$ & $\begin{array}{l}23 \cdot 4 \\
38 / 145 \\
6 / 150 \\
21 / 150 \\
43 / 150 \\
20 / 150 \\
65 / 150 \\
20 / 150 \\
38 / 150 \\
16 / 150 \\
27 / 150 \\
10 / 139 \\
31 / 150\end{array}$ & $\begin{array}{l}(5 \cdot 4) \\
(26 \%) \\
(4 \%) \\
(14 \%) \\
(29 \%) \\
(13 \%) \\
(43 \%) \\
(13 \%) \\
(25 \%) \\
(11 \%) \\
(18 \%) \\
(7 \%) \\
(21 \%)\end{array}$ & $\begin{array}{l}\text { NS } \\
<0.02 \\
<0.02 \\
\text { NS } \\
\text { NS } \\
\text { NS } \\
\text { NS } \\
<0.01 \\
\text { NS } \\
\text { NS } \\
<0.01 \\
<0.05 \\
<0.0001\end{array}$ \\
\hline
\end{tabular}

SD denotes standard deviation.

*In 19 women endocervical secretions were obscured by induced endocervical bleeding.

†Clinical cervicitis was defined as the presence of either endocervical mucopus or induced endocervical bleeding.

incubated in candle jars at $37 \pm 2^{\circ} \mathrm{C}$ within 4 hours of collection. Specimens for $C$ trachomatis were placed in two sucrose phosphate medium and transported on wet ice, then stored at $-70^{\circ} \mathrm{C}$ until cultured on cyclohexamide treated $\mathrm{McCoy}$ cells.

Women were informed of their results and if necessary treated with an appropriate antibiotic.

Data were analysed with SPSS/PC+ and Glim computer programmes, statistical methods used were the Chi squared test with Yates' correction, Fishers' exact test and the $t$ test. Logistic regression analysis was used to identify clinical signs independently associated with cervical infection.

Ethical approval was obtained from the Kenyatta National Hospital Ethics Committee.

\section{Results}

One hundred and seventy eight pregnant women were enrolled in the study during 1987 . Fifty three $(30 \%)$ were primiparous, and $40(22 \%)$ grand multipara. Most, $146(82 \%)$, were in the third trimester and only two $(1 \%)$ in the first trimester of pregnancy. Endocervical cultures for $C$ trachomatis were positive in $14(8 \%)$ of 178 women, and for N gonorrhoeae in 17 $(10 \%)$, of which seven $(41 \%)$ produced penicillinase. Twenty eight women $(16 \%)$ had cervical infection with either pathogen, three women $(1.7 \%)$ had dual infection.

Table 1 shows demographic and behavioural characteristics, symptoms, and signs compared with cervical infection. Features which were significantly associated with cervical infection were unmarried status (single, widowed or divorced), more than one sexual partner during pregnancy, a frothy vaginal discharge, induced bleeding and endocervical mucopus. In 19 women endocervical secretions were obscured by induced endocervical bleeding. If either endocervical mucopus or induced endocervical bleeding was observed "clinical cervicitis" was deemed to be present. Clinical cervicitis was more strongly associated with cervical infection than either endocervical mucopus or induced endocervical bleeding alone. Clinical cervicitis was present in 17 $(61 \%)$ of 28 women with cervical infection versus 31 $(21 \%)$ of $150, p<0.0001$. Symptoms of vaginal discharge, dysuria or abdominal pain were not associated with cervical infection.

\section{PREDICTING CERVICAL INFECTION}

Logistic regression analysis was performed to determine which variables were independently associated with cervical infection. The four variables identified on univariate analysis (unmarried status, more than one sexual partner during pregnancy, a frothy vaginal discharge, clinical cervicitis) were used in this analysis. Two variables were independently associated with cervical infection; the presence of clinical cervicitis, relative risk $4.2(95 \%$

Table 2 Sensitivity, specificity and positive predictive value of variables independently predictive of cervical infection

\begin{tabular}{|c|c|c|c|}
\hline Variable & Sensitivity ${ }^{\star}$ & Specificity ${ }^{\star}$ & $\begin{array}{l}\text { Positive } \\
\text { Predictive } \\
\text { Value }\end{array}$ \\
\hline $\begin{array}{l}>1 \text { Sexual Partner during Pregnancy } \\
\text { Clinical Cervicitis } \dagger \\
\text { Clinical Cervicitis and/or }>1 \text { Sexual Partner during Pregnancy } \\
\text { Clinical Cervicitis and }>1 \text { Sexual Partner during Pregnancy }\end{array}$ & $\begin{array}{l}18 \%(4-32) \\
61 \%(43-79) \\
68 \%(51-85) \\
11 \%(0-22)\end{array}$ & $\begin{array}{l}96 \%(93-99) \\
79 \%(73-86) \\
93 \%(88-97) \\
86 \%(81-91)\end{array}$ & $\begin{array}{l}0.45(0.16-0.75) \\
0.35(0.22-0.49) \\
0.35(0.22-0.47) \\
0.75(0.33-1.0)\end{array}$ \\
\hline
\end{tabular}

$\star 95 \%$ Confidence Intervals are shown in parentheses.

†Clinical cervicitis was defined as the presence of either endocervical mucopus or induced endocervical bleeding. 
CI $2 \cdot 2$ to $8 \cdot 0, \mathrm{p}<0.0001$ ) and having more than one sexual partner during pregnancy, relative risk 3.3 $(95 \%$ CI 1.4 to $7.6, \mathrm{p}<0.02)$. Table 2 shows the sensitivity, specificity, and positive predictive value of these two variables individually and together. A separate analysis was performed to examine clinical signs alone, and clinical cervicitis remained the only clinical sign associated with cervical infection.

\section{Discussion}

The prevalence rates of $C$ trachomatis ( $8 \%$ ) and $N$ gonorrhoeae $(10 \%)$ observed in this study, are comparable with previous reports from developing countries. $^{9-12}$ Pregnant women with cervical $C$ trachomatis or $N$ gonorrhoeae did not have an increased prevalence of abdominal pain, dysuria or vaginal discharge. Similarly these symptoms were found to be poor predictors of gonorrhoea in a study from Senegal by De Schampeliere and Van De Velden (reported in 13). Therefore if STDs are to be identified in pregnancy, screening is needed.

This study showed clinical cervicitis to be associated with cervical infection in pregnancy. Previous studies of non-pregnant women from developed countries have shown $C$ trachomatis to be associated with induced endocervical bleeding ${ }^{14}$ and with endocervical mucopus. ${ }^{14-18} \mathrm{~N}$ gonorrhoeae has been associated with endocervical mucopus ${ }^{18-19}$ and with cervicitis. ${ }^{20}$ Since $C$ trachomatis and $N$ gonorrhoeae are both associated with induced endocervical bleeding and with endocervical mucopus it seems reasonable to group both infections together when trying to identify infected women clinically.

How well does this screening test meet accepted principles? ?21 $^{21}$ STD in pregnancy are undoubtedly an important health problem in developing countries and if diagnosed early may be treated before complications ensue. Speculum examination is likely to be acceptable to most populations but may not always be available. The presence of clinical cervicitis should be easy to recognise; however, the sensitivity and positive predictive value of this sign alone was only moderate. Incorporation of a behavioural characteristic (more than one sexual partner during the current pregnancy) into the diagnostic algorithm improved its sensitivity and specificity. In order to refine this algorithm further, we would recommend that future research inquires about the lifetime total number of partners or number of partners in the last year, presence of genito-urinary symptoms in partners, and perhaps by testing the $\mathrm{pH}$ of vaginal discharge.

Whilst clinical cervicitis is likely to be a useful predictor of cervical infection in societies with a similar prevalence of infection, the value of a particular demographic or behavioural characteristic in a diagnostic algorithm is likely to vary widely from one culture to another. Therefore this algorithm cannot be automatically adopted to identify pregnant women at high risk of cervical infection in other societies. Diagnostic algorithms ought to be developed in the same setting as they will be used, and then evaluated prospectively. Their predictive value will be dependent on the prevalence of cervical infection, the observer, and local factors.

Women identified as being at high risk for cervical infection may either be treated for both $C$ trachomatis and $N$ gonorrhoeae, or referred for diagnostic tests. The availability of such tests and rates of return for treatment will determine the approach to be used. Although the costs of investigation or mass treatment of high risk women identified by this test are likely to be limited the use of a diagnostic algorithm should reduce the cost of diagnosis and make control of STDs in pregnancy more cost effective. Additionally if the evidence for $C$ trachomatis acting as a cofactor for acquisition of infection with human immunodeficiency virus is confirmed $^{22}$ then the need for STD control campaigns will become more urgent.

We thank Dr T A Bell and Prof R C Brunham for their comments on the manuscript, Tim Marshall for performing the regression analysis, Sisters Bosire and Ruminjo for help in the clinic, the staff of the Mother and Child Health Clinic in Pumwani for their co-operation, and Nairobi City Commission for permission to perform the study.

1 Sarrel PM, Pruett KA. Symptomatic gonorrhea during pregnancy. Obstet Gynecol 1968;32:670-3.

2 Wager GP, Martin DH, Eschenbach DA et al. Puerperal infectious morbidity: Relationship to mode of delivery and to antepartum Chlamydia trachomatis infection. Am J Obstet Gynecol 1980;138:1028-33.

3 Handsfield HH, Hodson WA, Holmes KK. Neonatal Gonococcal Infection 1. Orogastric contamination with $N$ gonorrhoeae. $J A M A$ 1973;225:697-701.

4 Plummer FA, Laga M, Brunham RC, et al. Postpartum upper genital tract infections in Nairobi, Kenya: Epidemiology, Etiology, and Risk factors. J Infect Dis 1987;156:92-8.

5 Fransen L, Nsanze H, Klauss V, et al. Ophthalmia neonatorum in Nairobi, Kenya: the roles of Neisseria gonorrhoeae and Chlamydia trachomatis. J Infect Dis 1986;153:862-9.

6 Laga M, Plummer FA, Nsanze H, et al. Epidemiology of Ophthalmia Neonatorum in Kenya. Lancet 1986;ii:1145-9.

7 Datta P, Laga M, Plummer FA et al. Infection and disease after perinatal exposure to Chlamydia trachomatis in Nairobi, Kenya. J Infect Dis 1988;158:524-8.

- 8 WHO: Nongonococcal urethritis and other selected sexually transmitted diseases of public health importance (1981) Tech Report 660.

9 WHO: WHO expert committee on venereal diseases and treponematoses (1986) Tech Report 736.

10 Nsanze H, Waigwa SRN, Mirza N, Plummer FA, Roelants P, Piot $P$. Chlamydial infections in selected populations in Kenya. In: Mardh P-A, Holmes KK, Oriel HD, Piot $\mathbf{P}$, Schacter J, eds. Chlamydial Infections. New York: Elsevier Biomedical Press, 1982:421-4.

11 Mabey DCW; Whittle HC. Genital and neonatal infection in a trachoma endemic area. Lancet 1982;ii:300-1.

12 Bentsi C, Klufio CA, Perine PL et al. Genital infections with Chlamydia trachomatis and Neisseria gonorrhoeae in Ghanaian women. Genitourin Med 1985;61:48-50. 
13 Meheus AZ. Practical approaches in developing nations. In: Holmes KK, Mardh PA, Sparling PF, Wiesner PJ, eds. Sexually transmitted diseases. New York: McGraw Hill, 1984:998-1008.

14 Handsfield HH, Jasman LL, Roberts PL, Hanson VW, Kothenbeutel RL, Stamm WE. Criteria for selective screening for Chlamydia trachomatis infection in women attending family planning clinics. JAMA 1986;255:1730-4.

15 Brunham RC, Paavonen J, Stevens CE et al. Mucopurulent cervicitis-The ionored counterpart in women of urethritis in men. N Engl J Med 1984;311:1-6.

16 Paavonen J, Critchlow CW, DeRouen T, et al. Etiology of cervical inflammation Am J Obstet Gynecol 1986;154:556-64.

17 Kent GP, Harrison R, Berman SM, Keenlyside RA. Screening for Chlamydia trachomatis infection in a sexually transmitted disease clinic, comparison of diagnostic with clinical and historical risk factors. Sex Transm Dis 1988;15:51-7.

18 Willmott FE. Mucopurulent cervicitis: a clinical entity? Genitourin Med 1988;64:169-71.

19 Paavonen J, Stevens CE, Wolner-Hanssen P et al. Colposcopic manifestations of cervical and vaginal infections. Obster
Gynecol Surv 1988;43:373-81.

20 Curran JW, Rendtorff RC, Chandler RW, Wiser WL, Robinson $H$. Female gonorrhea its relation to abnormal uterine bleeding, urinary tract symptoms and cervicitis. Obstet Gynecol 1975;45:195-8.

21 Wilson JMC. The worth of detecting occult disease. In: Sharp CLEH, Keen H, eds. Presymptomatic Detection and Early Diagnosis a critical appraisal. London: Pitman, 1968:141-63. 22 Pepin J, Plummer FA, Brunham RC, Piot P, Cameron DW, Ronald AR. The interaction of HIV infection and other sexually transmitted diseases: an opportunity for intervention. AIDS 1989;3:3-9.

MRB was supported by EEC grant No TSD M.423.UK(H). FAP is a recipient of scholarships from the Medical Research Council of Canada and the Canadian Life and Health Insurance Association.

Correspondence to MRB at 30 Merritts Brook Lane, Birmingham, B31 1 PN, UK. 